rotated sufficiently to restore articular congruity (Fig. 2). The osteotomy was fixed by an absorbable suture and the foot was immobilised in a plaster shoe cast for three to four weeks, with weight-bearing allowed as soon as tolerable.

Results. All patients were reviewed clinically and radiologically by an independent observer. There was no case of infection, avascular necrosis or pseudarthrosis. Pain relief was complete and all patients were able to enjoy sporting activities not possible before the surgery. Three patients had mild discomfort after prolonged jogging activities.

The loss of metatarsophalangeal flexion was $15^{\circ}$ (range $0^{\circ}$ to $30^{\circ}$ ) and the loss of metatarsophalangeal extension, $10^{\circ}$ (range $0^{\circ}$ to $30^{\circ}$ ) with no gait disturbance.

Judged by radiographs, the metatarsal was shortened by $2.5 \mathrm{~mm}$ (range 0 to $4 \mathrm{~mm}$ ) but no patient complained of pain from load transfer to the adjacent metatarsals.

Discussion. Numerous procedures have been proposed for symptomatic Freiberg's disease (Helal and Gibb 1987). Dorsiflexion osteotomy is the least destructive and the only one which restores the congruity of the joint in all cases with a large percentage of good results regardless of the stage of disease.

Presented in part at the American Academy of Orthopaedic Surgery, Anaheim, March 1991.

No benefits in any form have been received or will be received from a commercial party related directly or indirectly to the subject of this article.

\section{REFERENCES}

Gauthier G, Elbaz R. Freiberg's infraction: a subchondral bone fatigue fracture: a new surgical treatment. Clin Orthop 1979; $142: 93-5$.

Helal B, Gibb P. Freiberg's disease : a suggested pattern of management. Foot Ankle 1987; 8:94-102.

Kinnard P, Lirette R. Dorsiflexion osteotomy in Freiberg's disease. Foot Ankle 1989; 9:226-31.

Smillie IS. Freiberg's infraction (Köhler's second disease). J Bone Joint Surg [Br] 1957; 39-B:580.

Trott AW. Developmental disorders. In: Jahss MH, ed. Disorders of the foot. Vol 1. Philadelphia: WB Saunders, 1982:200-11.

\title{
SAFE PIN-DRILLING IN ILIZAROV'S PERCUTANEOUS TRANSFIXATION METHOD
}

\author{
JOHAN LAMMENS, BERT VANERMEN, GUY FABRY
}

Pin-drilling for external fixator devices always incurs some risk of neurovascular damage. The risks are greater when the limb is transfixed. In the Ilizarov method, multiple pins are inserted at various levels and angles. This requires considerable knowledge of cross-sectional topographical anatomy, and the variations that occur. We have developed a simple, safe technique for pindrilling, which is especially useful in the upper limb.

Method. Initially a 21-gauge needle is passed through a safe area until it touches bone. If no bleeding or muscular twitching occurs, the needle is removed and a 14-gauge intravenous catheter is inserted along the same track (Fig. 1). When the catheter is in close contact to the bone its obturator is withdrawn and the pin is inserted. Drilling can then be performed safely. Since only the entrance area is protected, one must always position the pins so that drilling takes place from the dangerous towards the safe side (Fig. 2). When olive wires are used to diminish shear stress forces, the catheter has to be split to allow the olive to pass.

Discussion. In the lower limb, there are sufficient 'safe

J. Lammens, MD, Orthopaedic Surgeon

B. Vanermen, MD, Orthopaedic Surgeon

G. Fabry, Professor of Orthopaedic Surgery, Head of Orthopaedic Department

University Hospital Pellenberg, Department of Orthopaedic Surgery, Weligerveld 1, 3212 Pellenberg, Belgium.

Correspondence to Dr J. Lammens.

(C) 1991 British Editorial Society of Bone and Joint Surgery 0301-620X/91/5R26\$2.00

J Bone Joint Surg [Br] 1991; 73-B: 865.

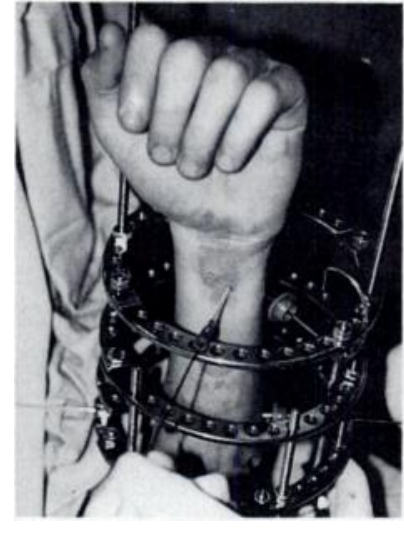

Fig. 1

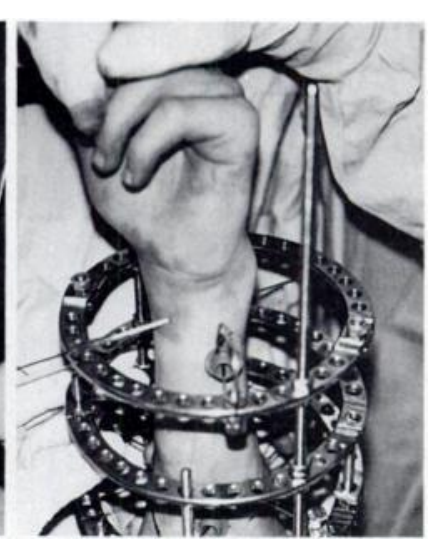

Fig. 2 areas' between arteries and nerves in relation to the bone, and most surgeons are familiar with the lower limb neurovascular structures. In the upper limb, however, the three important nerves are closer to each other and to the bone and, if damaged, can give rise to serious functional loss. To enhance stability, pin placement from different angles is necessary and may necessitate positioning pins very close to important structures.

The technique described allows for safe pin-drilling. Vessels and nerves are protected by the use of atraumatic probes, which do not cause any permanent damage. We believe that this method is particularly useful in severe congenital anomalies where the anatomy can be grossly abnormal.

No benefits in any form have been received or will be received from a commercial party related directly or indirectly to the subject of this article. 